Check for updates

Cite this: RSC Adv., 2017, 7, 42590

Received 20th May 2017

Accepted 16th August 2017

DOI: $10.1039 / \mathrm{c} 7 \mathrm{ra05687g}$

rsc.li/rsc-advances

\section{Propionic acid-based deep eutectic solvents: synthesis and ultra-deep oxidative desulfurization activity}

\begin{abstract}
Chun-feng Mao, (D) Rong-xiang Zhao* and Xiu-ping Li (D)
Propionic acid-based deep eutectic solvents $\left(\mathrm{C}_{3} \mathrm{H}_{6} \mathrm{O}_{2} / X \mathrm{ZnCl}_{2}, X\right.$ from 0.1 to 0.6$)$ were synthesized by stirring a mixture of propionic acid and zinc chloride at $100{ }^{\circ} \mathrm{C} . \mathrm{C}_{3} \mathrm{H}_{6} \mathrm{O}_{2} / 0.5 \mathrm{ZnCl}_{2}$ was characterized by infrared spectroscopy, electrospray ionization mass spectrometry and ${ }^{1} \mathrm{H}$ NMR spectroscopy. The oxidative desulfurization (ODS) of model oil and gasoline was investigated with $\mathrm{C}_{3} \mathrm{H}_{6} \mathrm{O}_{2} / 0.5 \mathrm{ZnCl}_{2} \mathrm{DESs}$ as an extractant and catalyst, and hydrogen peroxide $\left(\mathrm{H}_{2} \mathrm{O}_{2}\right)$ as an oxidant. Some influence factors such as acidity of DESs, reaction temperature, $\mathrm{H}_{2} \mathrm{O}_{2}$ to sulfur $\left(\mathrm{H}_{2} \mathrm{O}_{2} / \mathrm{S}\right)$ molar ratio, and volume ratio of DESs to oil were studied. The results indicated that the desulfurization rates of dibenzothiophene (DBT), 4,6-dimethyl-dibenzothiophene (4,6-DMDBT), and gasoline can reach $99.42 \%, 98.80 \%$, and $66.67 \%$, respectively, under conditions of $30{ }^{\circ} \mathrm{C}$, an $\mathrm{H}_{2} \mathrm{O}_{2} / \mathrm{S}$ molar ratio of 4 , and volume ratio of DESs to oil of $0.15 / 1$ over a period of $180 \mathrm{~min}$. The desulfurization rate of DBT in model oil reached $96.31 \%$ after five recycles in the $\mathrm{C}_{3} \mathrm{H}_{6} \mathrm{O}_{2} / 0.5 \mathrm{ZnCl}_{2}-\mathrm{H}_{2} \mathrm{O}_{2}$ systems.
\end{abstract}

\section{Introduction}

With the rapid development of the automotive industry, the problems of pollutant emissions are becoming increasingly serious. In order to reduce the environmental pollution caused by $\mathrm{SO}_{x}$ produced through burning fuel, ${ }^{1}$ many countries have laid down strict environmental regulations to limit the sulfur content of fuel oil to under $10 \mathrm{mg} \mathrm{L}^{-1} .^{2}$ The low concentration of sulfur compounds in oil has been a hot spot in academic research.

Hydrogenation desulfurization (HDS) ${ }^{3,4}$ is the most effective method for removing aliphatic sulfide in fuel. However, HDS has some limitations, including stringent operating conditions such as high temperature, high pressure ${ }^{5}$ and low desulfurization activity for DBT and its derivatives. ${ }^{6,7}$ In recent years, as a supplement of HDS, oxidative desulfurization (ODS) ${ }^{8-10}$ has attracted wide attention. Oxidative desulfurization has some advantages such as mild reaction conditions and a high desulfurization rate for DBT and its derivatives. In the ODS process, organic sulfides in fuel were oxidized to the corresponding sulfoxides and sulfones under the action of catalyst and hydrogen peroxide. ${ }^{11}$ There are several oxidants, including $\mathrm{H}_{2} \mathrm{O}_{2},{ }^{12}$ molecular oxide, ${ }^{13}$ ozone $^{14}$ and organic peroxide. ${ }^{15}$ However, $\mathrm{H}_{2} \mathrm{O}_{2}$ is the most used in the ODS process because it produces harmless by products. ${ }^{16}$

College of Chemistry, Chemical Engineering and Environmental Engineering, Liaoning Shihua University, Fushun 113001, China. E-mail: maochunfeng555@163.com; zylhzrx@126.com
Deep eutectic solvents (DESs), analogues of ionic liquids (ILs), can be obtained by simply stirring the mixture containing two or three safe and cheap raw materials. DESs possess some special advantages ${ }^{17}$ such as non-toxic, biodegradability, low vapor pressure and excellent thermal/chemical stability. DESs have been applied in various fields ${ }^{18}$ such as separation, catalysis, electrochemistry and synthesis. Meanwhile, DESs have also been used in extractive desulfurization. Gano et al. ${ }^{19}$ found extractive desulfurization rates of $64 \%$ and $44 \%$ for DBT and thiophene (TH) using $\mathrm{FeCl}_{3}$-based DESs as extractant. Li et al. ${ }^{20}$ found that a series of ammonium-based DESs and the extractive desulfurization rate of $82.83 \%$ can be obtained for one cycle. Gano et $a .^{21}$ found that extractive desulfurization rate of $\mathrm{SnCl}_{2} \cdot 2 \mathrm{H}_{2} \mathrm{O}$-based DESs can be up to $69.57 \%$ and $47.28 \%$ for DBT and TH. Tang et al. ${ }^{8}$ reported that $84.5 \%$ extractive desulfurization rate of arenium ion deep eutectic solvents for real oil can be achieved. Li et al. ${ }^{22}$ found the synthesis of carboxylic acid-based DESs and its application to extractive desulfurization, and desulfurization rates of $80.47 \%, 81.75 \%$ and $72 \%$ for DBT, BT and TH in a single stage. In order to achieve higher desulfurization rate, the oxidative desulfurization exhibits higher desulfurization rate than extractive desulfurization rate. For instance, Yin et al. ${ }^{23}$ reported that choline chloride $/ p$-toluenesulfonic acid $(\mathrm{ChCl} / p \mathrm{TsOH})$ and tetrabutylammonium chloride/ $p$-toluenesulfonic acid (TBAC/ $p$-TsOH) were synthesized and their oxidative desulfurization rates were $99.99 \%$ each. Lü et $a .^{24}$ found a series of oxalate-based deep eutectic solvents and the oxidative desulfurization rate of TBAC 2OXA was $91 \%$. Liu et al. ${ }^{25}$ reported that the removal rate of DBT can be up to $99.1 \%$ using choline chloride/polyethylene glycol 
(ChCl/PEG) DESs. Zhu et al. $^{26}$ reported that the removal rate of DBT can reach $98.6 \%$ using air, extractant, irradiation of UV and isobutyraldehyde via liquid-liquid extraction and photochemical oxidative desulfurization, and the removal rate of DBT can reach $95.3 \%$ using a temperature-responsive magnetic ionic liquid (IL) $N$-butylpyridinium tetrachloroferrate $\left([\mathrm{BPy}]\left[\mathrm{FeCl}_{4}\right]\right)$ as a catalyst. ${ }^{27}$ Our research group ${ }^{28}$ reported that the removal rate of DBT in model oil can go up to $99.23 \%$ using $\mathrm{C}_{9} \mathrm{H}_{10} \mathrm{O}_{2} 0.5$ $\mathrm{ZnCl}_{2}$ DESs under optimal reaction conditions. In this study, $\mathrm{C}_{3} \mathrm{H}_{6} \mathrm{O}_{2} / X \mathrm{ZnCl}_{2}$ ( $X$ from 0.1 to 0.6 ) DES was synthesized by stirring a mixture of propionic acid and zinc chloride under $100{ }^{\circ} \mathrm{C}$. Compared with phenylpropanoic acid-based DESs and reported literature ${ }^{23-27}$ the raw material is more easily obtained and inexpensive. Meanwhile, oxidative desulfurization activity of $\mathrm{C}_{3} \mathrm{H}_{6} \mathrm{O}_{2} / X \mathrm{ZnCl}_{2}$ can attach to effective of reported literature under more mild condition. In the ODS system, $\mathrm{C}_{3} \mathrm{H}_{6} \mathrm{O}_{2} / 0.5$ $\mathrm{ZnCl}_{2}$ DESs were used as an extractant and a catalyst, and $\mathrm{H}_{2} \mathrm{O}_{2}$ as an oxidant. Formation and structure of $\mathrm{C}_{3} \mathrm{H}_{6} \mathrm{O}_{2} / 0.5 \mathrm{ZnCl}_{2}$ have been confirmed by FT-IR, ${ }^{1} \mathrm{H}$ NMR and ESI-MS spectroscopies. The reaction conditions such as acidity of DESs, reaction temperature, molar ratio of $\mathrm{H}_{2} \mathrm{O}_{2} / \mathrm{S}$, and volume ratio of DESs to oil were optimized. Furthermore, catalytic oxidative desulfurization mechanism of DBT in model oil is discussed in detail.

\section{Experiment}

\subsection{Materials}

DBT (98\%), BT (97\%), TH (99.8\%) and 4,6-DMDBT (98\%) were purchased from Aladdin Reagent Co., Ltd. $\mathrm{H}_{2} \mathrm{O}_{2}$ (30 wt\%), $n$-octane (AR grade), propionic acid (AR grade), zinc chloride (AR grade) and carbon tetrachloride (AR grade) were purchased from Sinopharm Chemical Reagent Co., Ltd.

\subsection{Synthesis and characterization of deep eutectic solvents}

$\mathrm{C}_{3} \mathrm{H}_{6} \mathrm{O}_{2} \cdot X \mathrm{ZnCl}_{2}$ ( $X$ from 0.1 to 0.6 ) DESs were synthesized using zinc chloride $\left(\mathrm{ZnCl}_{2}\right)$ and propionic acid as raw materials. The mixture of zinc chloride $\left(\mathrm{ZnCl}_{2}\right)$ and propionic acid was heated at $100{ }^{\circ} \mathrm{C}$ until a homogeneous liquid was formed. The synthesis of DES is shown in Fig. 1.

In order to further analyze the structure, some characterizations were performed. Gas chromatography was determined on an Agilent 7890A GC with an FID detector using a 30 m packed HP5 column. FT-IR (NEXUS8700, Thermo Electron, $\mathrm{KBr}$ ), ${ }^{1} \mathrm{H}$ NMR (Bruker Avance $600 \mathrm{MHz}$ spectrometer, Germany) and ESI-MS (Bruker Daltonics APEX-II, USA) spectroscopies were also used to analyzed the samples. GC-MS analysis was conducted using an Agilent 7890/5975C-GC/MSD to characterize the oxidized sulfur compounds in deep eutectic solvents after the desulfurization reaction. The sulfur

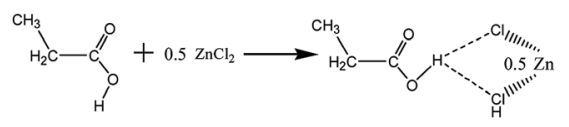

Fig. 1 Synthesis of DESs. content of gasoline was measured using a WK-2D comprehensive micro coulomb analyzer (Jiangsu jiang electric analysis instrument Co., Ltd).

\subsection{Desulfurization procedure and recycling}

A model oil of $500 \mu \mathrm{g} \mathrm{mL}{ }^{-1}$ was prepared by dissolving $1.437 \mathrm{~g}$ DBT in $500 \mathrm{~mL} n$-octane. The ODS experiments were performed in a three-necked flask. The mixture of model oil, $\mathrm{H}_{2} \mathrm{O}_{2}$ and DESs was stirred at $30^{\circ} \mathrm{C}$ for $180 \mathrm{~min}$. The upper oil phase was taken out after $20 \mathrm{~min}$ and analyzed by gas chromatography on an Agilent 7890A GC with an FID detector using a $30 \mathrm{~m}$ packed HP5 column. The desulfurization rate is calculated by following equation.

Desulfurization rate $=\left(S_{\text {tot }}-S_{\text {res }}\right) / S_{\text {tot }} \times 100 \%$

where $S_{\text {tot }}$ is the total sulfur concentration and $S_{\text {res }}$ is the residual sulfur concentration after $t$ min. The DESs phase was treated using a rotary evaporator and $\mathrm{CCl}_{4}$. The water in DESs phase was removed using a rotary evaporator. The oxidative product, dibenzothiophene sulfone $\left(\mathrm{DBTO}_{2}\right)$ was extracted by $\mathrm{CCl}_{4}$ three times every $30 \mathrm{~min}$; subsequently, $\mathrm{CCl}_{4}$ in DESs phase was removed using a rotary evaporator. The recovered DESs were reused in the next ODS.

\section{Results and discussion}

\subsection{FT-IR characterization}

To determine the structure of the DES, FT-IR analysis of $\mathrm{ZnCl}_{2}, \mathrm{C}_{3} \mathrm{H}_{6} \mathrm{O}_{2}$ and $\mathrm{C}_{3} \mathrm{H}_{6} \mathrm{O}_{2} / 0.5 \mathrm{ZnCl}_{2}$ was performed. Results of analysis are shown in Fig. 2. The characteristic peaks of propionic acid at $934 \mathrm{~cm}^{-1}$ (bending vibration peak of $\mathrm{OH}$, out of plane); 1079 and $1238 \mathrm{~cm}^{-1}$ (stretching vibration peak of $\mathrm{C}-\mathrm{C}$ ); $1291 \mathrm{~cm}^{-1}$ (stretching vibration peak of $\mathrm{C}-\mathrm{O}$ ); 1418 and $1469 \mathrm{~cm}^{-1}$ (bending vibration peak of $\mathrm{C}-\mathrm{H}$ ); $1717 \mathrm{~cm}^{-1}$ (stretching vibration peak of $\mathrm{C}=\mathrm{O}$ ); 2558, 2641 and $2981 \mathrm{~cm}^{-1}$ (stretching vibration peak of $\mathrm{OH}$ ) can also be observed in the DES. The peaks of $\mathrm{OH}$ groups in $\mathrm{ZnCl}_{2}$ (3300$3700 \mathrm{~cm}^{-1}$ ) and propionic acid (2800 and $3300 \mathrm{~cm}^{-1}$ ) appear to be shifted and broadened due to the formation of $\mathrm{H}$-bonding in the DES. ${ }^{29}$

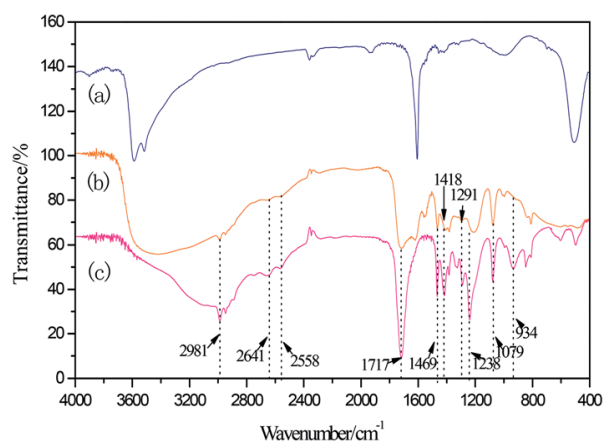

Fig. 2 FT-IR spectra of (a) $\mathrm{ZnCl}_{2}$; (b) $\mathrm{C}_{3} \mathrm{H}_{6} \mathrm{O}_{2} / 0.5 \mathrm{ZnCl}_{2}$; (c) $\mathrm{C}_{3} \mathrm{H}_{6} \mathrm{O}_{2}$. 


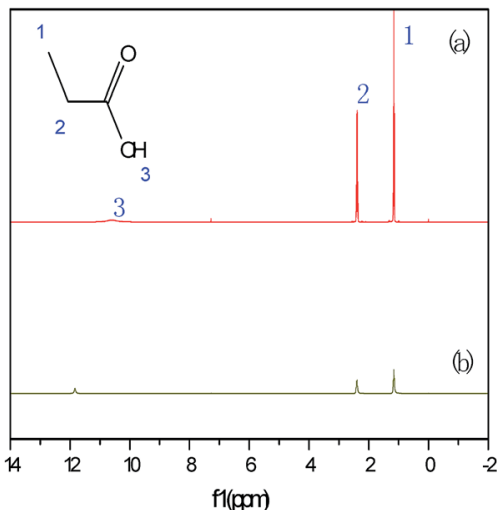

Fig. $3{ }^{1} \mathrm{H}$ NMR of (a) $\mathrm{C}_{3} \mathrm{H}_{6} \mathrm{O}_{2}$; (b) $\mathrm{C}_{3} \mathrm{H}_{6} \mathrm{O}_{2} / 0.5 \mathrm{ZnCl}_{2}$.

\section{2 $\quad{ }^{1} \mathrm{H}$ NMR characterization}

To further determine the interaction between $\mathrm{ZnCl}_{2}$ and $\mathrm{C}_{3} \mathrm{H}_{6} \mathrm{O}_{2}, \mathrm{C}_{3} \mathrm{H}_{6} \mathrm{O}_{2}$ and $\mathrm{C}_{3} \mathrm{H}_{6} \mathrm{O}_{2} / 0.5 \mathrm{ZnCl}_{2}$ were characterized using ${ }^{1} \mathrm{H}$ NMR. From the results shown in Fig. 3, it can be seen that the peak positions of 1 and 2 do not change, but peak intensity is obviously weak in DES. The peak positions of 3 obviously shifted from $10.8 \mathrm{ppm}$ to $11.9 \mathrm{ppm}$. It can be shown that $\mathrm{H}$ of $\mathrm{OH}$ occur the moving of electric charge. ${ }^{30} \mathrm{Hence}$, it can be concluded that DESs have been formed between $\mathrm{C}_{3} \mathrm{H}_{6} \mathrm{O}_{2}$ and $\mathrm{ZnCl}_{2}$.

\subsection{ESI-MS spectra}

The structures of $\mathrm{C}_{3} \mathrm{H}_{6} \mathrm{O}_{2} / 0.5 \mathrm{ZnCl}_{2}$ were further determined by ESI-MS spectral analysis. As shown in Fig. 4, from the ESI-MS spectra of $\mathrm{C}_{3} \mathrm{H}_{6} \mathrm{O}_{2} / 0.5 \mathrm{ZnCl}_{2}$, intensive peaks can be observed at $m / z=171,309,444$, which correspond to $\mathrm{ZnCl}_{3}{ }^{-}, \mathrm{Zn}_{2} \mathrm{Cl}_{5}{ }^{-}$, $\mathrm{Zn}_{3} \mathrm{Cl}_{7}{ }^{-}$. This result is in accordance with a previous report. ${ }^{31}$ It can be concluded that $\mathrm{C}_{3} \mathrm{H}_{6} \mathrm{O}_{2} / 0.5 \mathrm{ZnCl}_{2}$ has been formed.

\subsection{Influence of different Lewis acidic DESs on ODS}

The Lewis acidity of the DESs depends on the molar ratio of propionic acid to zinc chloride, which has a significant effect on desulfurization rate. A series of $\mathrm{C}_{3} \mathrm{H}_{6} \mathrm{O}_{2} / X \mathrm{ZnCl}_{2}(X$ from 0.1 to 0.6) were prepared by changing the molar ratio of $\mathrm{C}_{3} \mathrm{H}_{6} \mathrm{O}_{2}$ to $\mathrm{ZnCl}_{2}$. As shown in Fig. 5, the desulfurization rate increases when the molar ratio of $\mathrm{C}_{3} \mathrm{H}_{6} \mathrm{O}_{2}$ to $\mathrm{ZnCl}_{2}$ was increased from 0.1

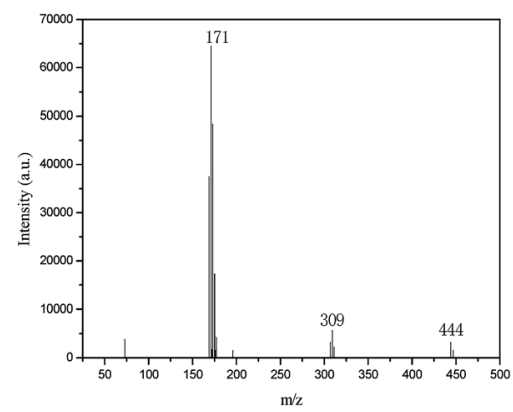

Fig. 4 ESI-MS spectra of $\mathrm{C}_{3} \mathrm{H}_{6} \mathrm{O}_{2} / 0.5 \mathrm{ZnCl}_{2}$.

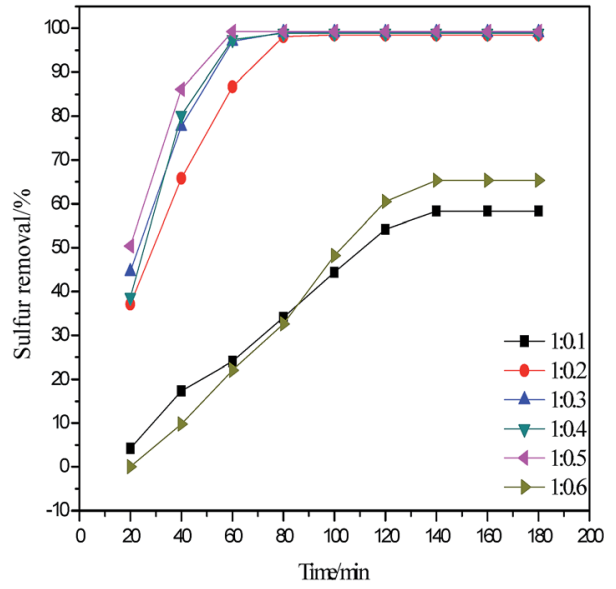

Fig. 5 Influence of different acidic DESs on oxidative desulfurization $\left(V\right.$ (oil) $=5 \mathrm{~mL}, V\left(\right.$ DESs) $/$ (oil) $\left.=0.2 / 1, n\left(\mathrm{H}_{2} \mathrm{O}_{2}\right) / n(\mathrm{~S})=6,40^{\circ} \mathrm{C}\right)$.

to 0.2. Desulfurization rate decreases when the molar ratio of $\mathrm{C}_{3} \mathrm{H}_{6} \mathrm{O}_{2}$ to $\mathrm{ZnCl}_{2}$ exceeds 0.6 and the desulfurization rate is stable when molar ratio of $\mathrm{C}_{3} \mathrm{H}_{6} \mathrm{O}_{2}$ to $\mathrm{ZnCl}_{2}$ ranges from 0.2 to 0.5 . This result is in good agreement with previous literature. ${ }^{25}$ When the molar ratio of $\mathrm{C}_{3} \mathrm{H}_{6} \mathrm{O}_{2}$ to $\mathrm{ZnCl}_{2}$ was increased, the Lewis acidity of the catalyst was also enhanced. In a certain range, the strong acidity is beneficial for the oxidation desulfurization process because $\mathrm{H}_{2} \mathrm{O}_{2}$ produces hydroxyl radicals ' $\mathrm{OH}$ and oxygen radicals $\mathrm{O}^{\prime}$. However, very strong acidity results in direct decomposition of hydrogen peroxide ${ }^{32}$ to produce oxygen and water. Therefore, the highest desulfurization rate of 99.23\% in 60 min was obtained when the molar ratio of $\mathrm{C}_{3} \mathrm{H}_{6} \mathrm{O}_{2}$ to $\mathrm{ZnCl}_{2}$ is $1: 0.5$. Therefore, $\mathrm{C}_{3} \mathrm{H}_{6} \mathrm{O}_{2} / 0.5 \mathrm{ZnCl}_{2}$ used as extractant and catalyst undergoes the following desulfurization experiments.

\subsection{Influence of the reaction temperature on ODS}

The reaction temperature is an important factor for ODS. As shown in Fig. 6, when the reaction time exceeds $100 \mathrm{~min}$, the desulfurization rate remains unchanged. The higher the

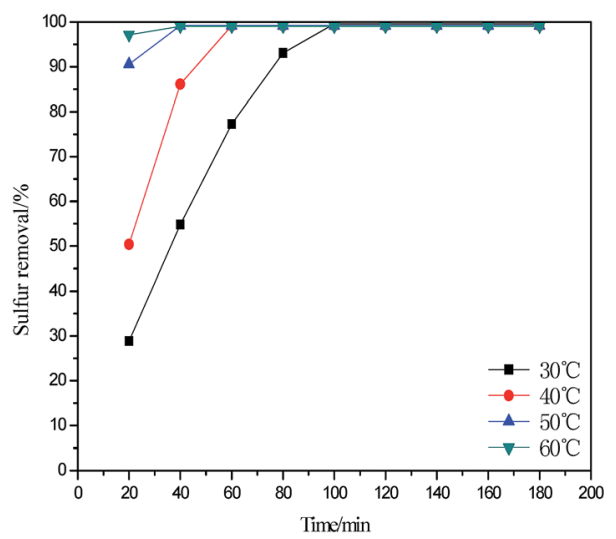

Fig. 6 Influence of reaction temperature on oxidative desulfurization $\left(V(\right.$ oil $)=5 \mathrm{~mL}, V($ DESs $) / V($ oil $\left.)=0.2 / 1, n\left(\mathrm{H}_{2} \mathrm{O}_{2}\right) / n(\mathrm{~S})=6\right)$. 


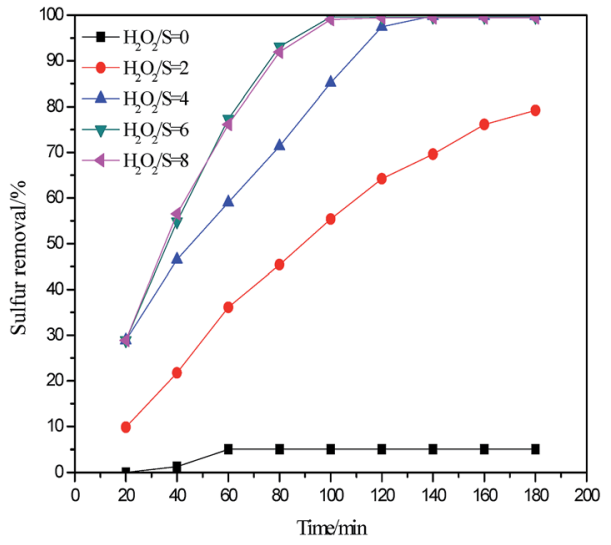

Fig. 7 Influence of $\mathrm{H}_{2} \mathrm{O}_{2} / \mathrm{S}$ molar ratio on oxidative desulfurization $\left(V(\right.$ oil $)=5 \mathrm{~mL}, V\left(\right.$ DESs) $/ V$ (oil) $\left.=0.2 / 1,30^{\circ} \mathrm{C}\right)$.

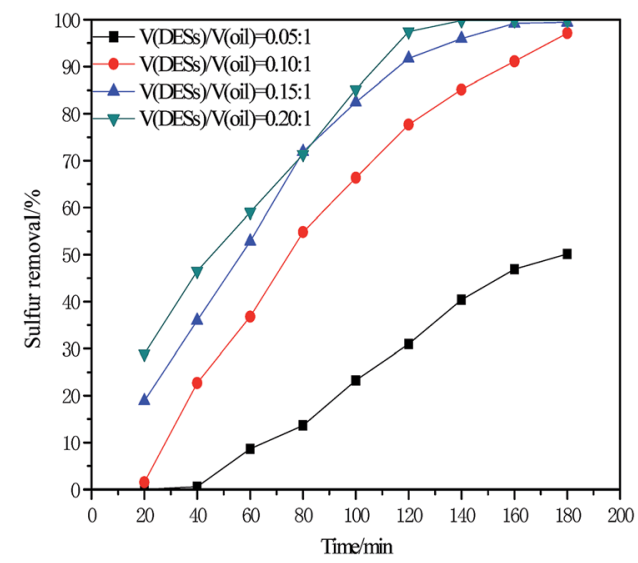

Fig. 8 Influence of $V(D E S s) / V$ (oil) on oxidative desulfurization $(V$ (oil) $=$ $\left.5 \mathrm{~mL}, n\left(\mathrm{H}_{2} \mathrm{O}_{2}\right) / n(\mathrm{~S})=4,30^{\circ} \mathrm{C}\right)$.

reaction temperature, ranging from $30{ }^{\circ} \mathrm{C}$ to $60{ }^{\circ} \mathrm{C}$, the shorter the balance time of desulfurization reaction. The trend is consistent with a previous study. ${ }^{33}$ However, the reaction temperature of $30^{\circ} \mathrm{C}$ was considered as the optimal reaction temperature since low temperature ensures safety and low cost.

\subsection{Influence of $\mathrm{H}_{2} \mathrm{O}_{2} / \mathrm{S}$ molar ratio on ODS}

In order to achieve industrialization for ODS, it is very important to use small dosages of $\mathrm{H}_{2} \mathrm{O}_{2}$. As shown in Fig. 7, the desulfurization process was performed using $\mathrm{C}_{3} \mathrm{H}_{6} \mathrm{O}_{2} / 0.5 \mathrm{ZnCl}_{2}$ DESs as an extractant and a catalyst under different $\mathrm{H}_{2} \mathrm{O}_{2} / \mathrm{S}$ molar ratios at $30{ }^{\circ} \mathrm{C}$. The desulfurization rate obviously increases from $5.06 \%$ to $99.81 \%$ when $\mathrm{H}_{2} \mathrm{O}_{2} / \mathrm{S}$ molar ratio changes from 0 to 4 . According to the stoichiometric ratio, $2 \mathrm{~mol}$ $\mathrm{H}_{2} \mathrm{O}_{2}$ was required to oxidize $1 \mathrm{~mol}$ of DBT into sulfone. However, a higher desulfurization rate of $99.81 \%$ is obtained at an $\mathrm{H}_{2} \mathrm{O}_{2} / \mathrm{S}$ molar ratio of 4 instead of 2; this could be ascribed to loss and decomposition of some $\mathrm{H}_{2} \mathrm{O}_{2}$ in ODS process. ${ }^{34}$ Meanwhile, the desulfurization rate is maintained when $\mathrm{H}_{2} \mathrm{O}_{2} / \mathrm{S}$ molar ratio continually increases. Hence, $\mathrm{H}_{2} \mathrm{O}_{2} / \mathrm{S}$ molar ratio of 4 was selected as the optimal $\mathrm{H}_{2} \mathrm{O}_{2} / \mathrm{S}$ molar ratio for $\mathrm{C}_{3} \mathrm{H}_{6} \mathrm{O}_{2} / 0.5$ $\mathrm{ZnCl}_{2}$ system in the present study.

\subsection{Influence of volume ratio of DESs to oil on ODS}

DESs were used as an extractant and catalyst in the ODS system. The amount of DES has an important influence on sulfur removal. As shown in Fig. 8, the desulfurization rate increased from $50.19 \%$ to $99.42 \%$ when the volume ratio of DESs to oil was increased from $0.05 / 1$ to $0.15 / 1$. However, the desulfurization rate slightly increases when volume ratio of DESs to oil was increased from $0.15 / 1$ to $0.20 / 1$. Hence, the volume ratio of DESs to oil of $0.15 / 1$ was selected as the excess volume ratio of DESs to oil results in increased costs.

\subsection{Influence and kinetic analysis of different sulfur compounds on ODS}

The oxidative desulfurization experiment of four sulfur compounds such as DBT, 4,6-DMDBT, BT and TH were performed under optimal reaction conditions. As shown in Fig. 9(a), the desulfurization rate follows the order: DBT
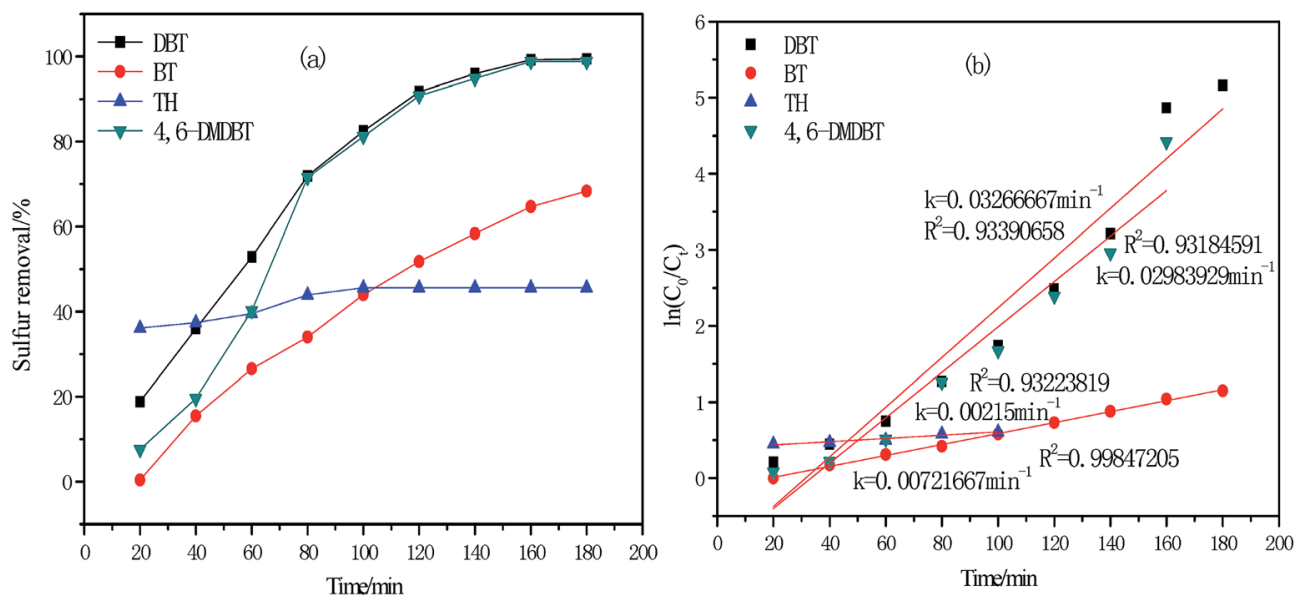

Fig. 9 (a) Influence of different sulfur compounds on oxidative desulfurization (V(oil) $\left.=5 \mathrm{~mL}, V(\mathrm{DESs}) / \mathrm{V}(\mathrm{oil})=0.15 / 1, n\left(\mathrm{H}_{2} \mathrm{O}_{2}\right) / n(\mathrm{~S})=4,30{ }^{\circ} \mathrm{C}\right) ;(\mathrm{b})$ kinetic analysis of different sulfur compounds. 


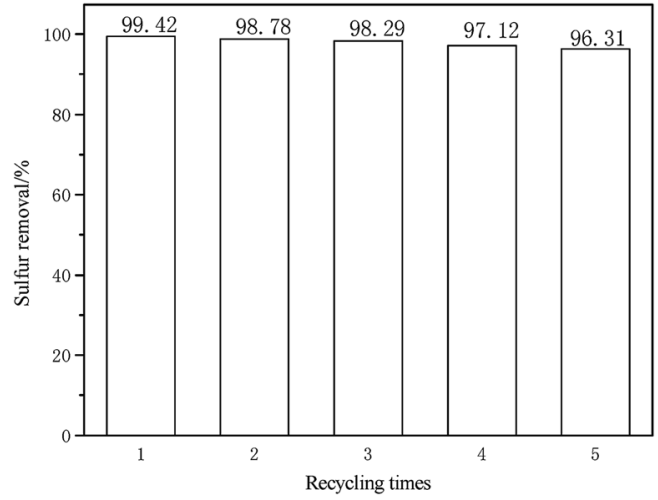

Fig. 10 Influence of recycle and regeneration of DESs on oxidative desulfurization $\left(V(\right.$ oil $)=5 \mathrm{~mL}, V(\mathrm{DESs}) / \mathrm{V}$ (oil) $=0.15 / 1, n\left(\mathrm{H}_{2} \mathrm{O}_{2}\right) / n(\mathrm{~S})=4$, $\left.30{ }^{\circ} \mathrm{C}\right)$.

$(99.42 \%)>4,6$-DMDBT $(98.80 \%)>\mathrm{BT}(68.36 \%)>\mathrm{TH}$ (45.65\%). This order of desulfurization rate agreed with a previous study. ${ }^{22}$ The desulfurization order is correlated to the electron cloud density of the sulfur atom in organic sulfides such as 4,6-DMDBT (5.760), DBT (5.758), BT (5.739) and TH (5.696). ${ }^{35,36}$ Larger electron cloud density and higher desulfurization activity are obtained. However, the desulfurization rate of 4,6-DMDBT was influenced by steric hindrance of two methyl groups even through the electron cloud density of 4,6-DMDBT is the largest in four sulfurs. Hence, the desulfurization rate of 4,6-DMDBT is slightly lower than that of DBT.

Meanwhile, it is science and strictness with the combination of theoretical method and experimental method. On the basis of experimental data and related research, it is known that ODS follows the first order reaction kinetics equation. ${ }^{37}$

$$
-\frac{\mathrm{d} C_{t}}{\mathrm{dt}}=k C_{t}
$$

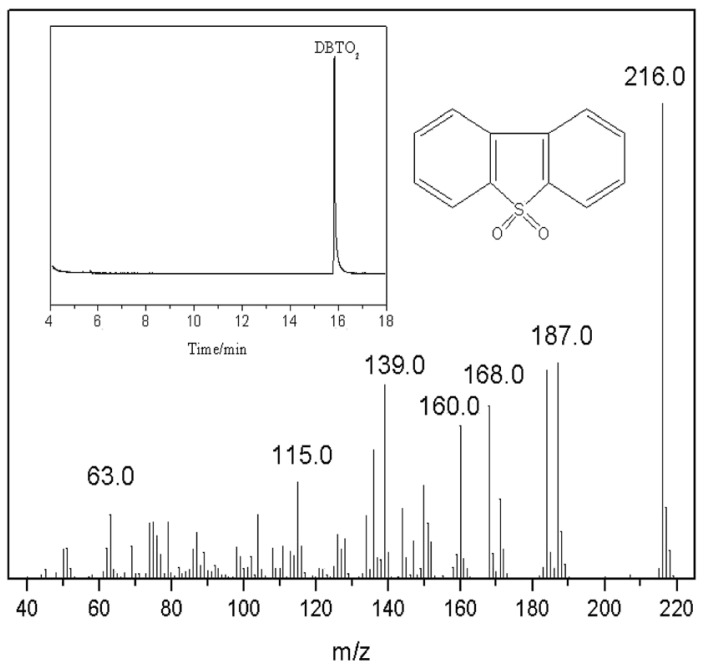

Fig. 11 Analysis of oxidation products using GC-MS.

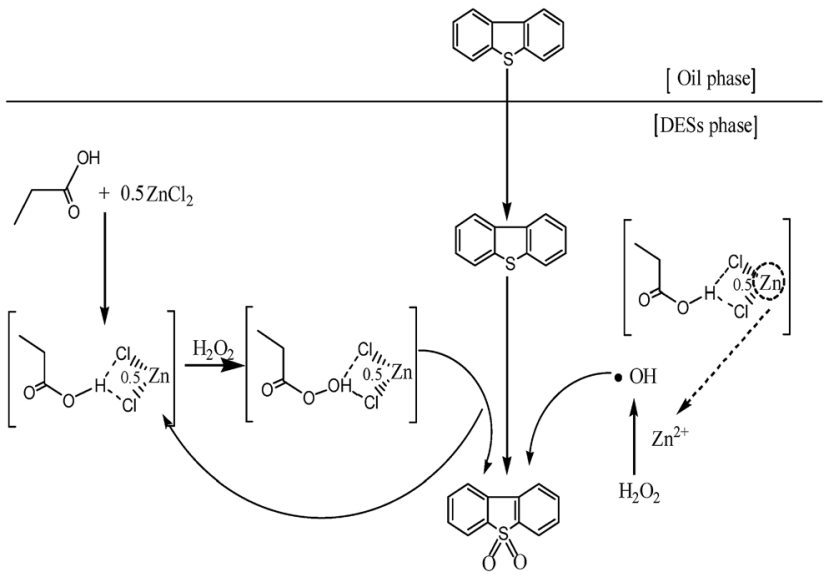

Fig. 12 Mechanism of oxidative desulfurization.

$$
\ln \frac{C_{0}}{C_{t}}=k t
$$

where $C_{0}$ is the total sulfur concentration, $C_{t}$ is the residual sulfur concentration after $t \mathrm{~min}, R^{2}$ is the correlation coefficient and $k$ is the reaction kinetics constant. As shown in Fig. 9(b), the reaction kinetics constant $k$ is $0.03266667,0.02983929$, 0.00721667 and $0.00215 \mathrm{~min}^{-1}$ for DBT, 4,6-DMDBT, BT and TH, respectively. The correlation coefficient $R^{2}$ is 0.93390658 , $0.93184591,0.99847205$ and 0.93223819 for DBT, 4,6-DMDBT, BT and TH, respectively. It can be concluded that the theory is in agreement with the experiment.

\subsection{Recovery and regeneration of DESs}

The recovery and regeneration of DESs is very important for large-scale applications. After every oxidative desulfurization experiment, the upper oil phase was separated using a separating funnel. Oxidative product of DBT in DESs phase at the bottom was separated and extracted using $\mathrm{CCl}_{4}$ as an extractant. $\mathrm{CCl}_{4}$ was removed using a rotary evaporator. The desulfurization experiment was performed using recovered DESs, fresh $\mathrm{H}_{2} \mathrm{O}_{2}$ and model oil for the next cycle. As shown in Fig. 10, the desulfurization rate was decreased to $96.31 \%$ after five recycles. It can be attributed to the regeneration of DESs containing some oxidative product of DBT and partly to DESs losses in oil during recycling experiments..$^{38,39}$

\subsection{Analysis of oxidation products using GC-MS}

In order to identify the oxidation products of DBT, after the oxidative desulfurization reaction, a reverse extraction experiment was conducted using $\mathrm{CCl}_{4}$ as an extractant and detected by GC-MS analysis. The results of the analysis are shown in Fig. 11. It can be seen that dibenzothiophene sulfone $\left(\mathrm{DBTO}_{2}\right.$, $m / z=216.0$ ) exists in carbon tetrachloride ${ }^{40}$ and no other types of sulfur-containing compounds were obtained. In other words, under optimum conditions, DBT could be completely removed and converted into $\mathrm{DBTO}_{2}$. 
Table 1 Comparison of catalytic oxidative desulfurization of model oil and real oil by $\mathrm{C}_{3} \mathrm{H}_{6} \mathrm{O}_{2} / 0.5 \mathrm{ZnCl}$ and other acidic ionic liquids

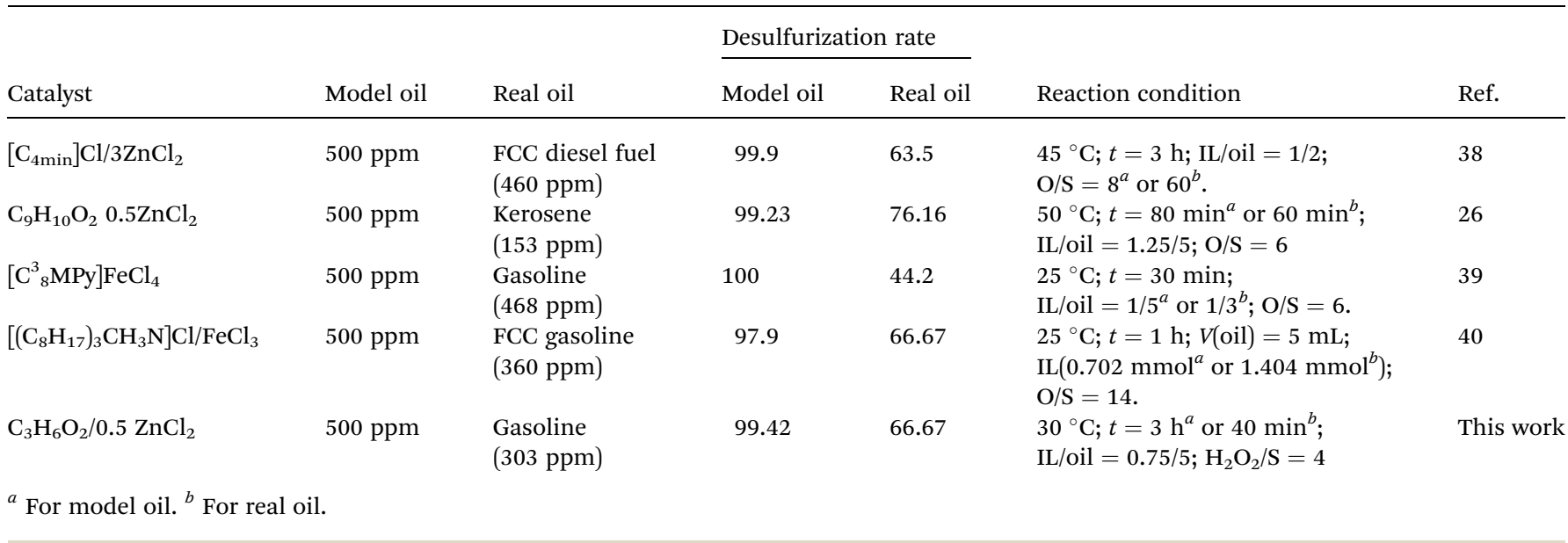

\subsection{Catalytic mechanism of DESs for oxidative desulfurization}

Based on the experimental results and analysis, the proposed process of catalytic extractive oxidative desulfurization of DBT in the model oil in the presence of $\mathrm{C}_{3} \mathrm{H}_{6} \mathrm{O}_{2} / 0.5 \mathrm{ZnCl}_{2}$ DESs and $\mathrm{H}_{2} \mathrm{O}_{2}$ is shown in Fig. 12. The entire oxidative desulfurization process can be described as follows. First, DBT in the model oil is extracted to DESs phase. Second, DBT is oxidized to $\mathrm{DBTO}_{2}$ by the action of hydroxyl radicals and peroxy- $\mathrm{C}_{3} \mathrm{H}_{6} \mathrm{O}_{2} / 0.5 \mathrm{ZnCl}_{2}$. The hydroxyl radicals are produced by the reaction of $\mathrm{H}_{2} \mathrm{O}_{2}$ and the zinc ions in $\mathrm{C}_{3} \mathrm{H}_{6} \mathrm{O}_{2} / 0.5 \mathrm{ZnCl}_{2} .{ }^{28}$ The formation of peroxy$\mathrm{C}_{3} \mathrm{H}_{6} \mathrm{O}_{2} / 0.5 \mathrm{ZnCl}_{2}$ is the result of oxidation of $\mathrm{C}_{3} \mathrm{H}_{6} \mathrm{O}_{2} / 0.5 \mathrm{ZnCl}_{2}$ by $\mathrm{H}_{2} \mathrm{O}_{2}$. In the ODS process, DBT is oxidized to $\mathrm{DBTO}_{2}$ when peroxy- $\mathrm{C}_{3} \mathrm{H}_{6} \mathrm{O}_{2} / 0.5 \mathrm{ZnCl}_{2}$ is transformed into $\mathrm{C}_{3} \mathrm{H}_{6} \mathrm{O}_{2} / 0.5 \mathrm{ZnCl}_{2}$. The oxidative desulfurization process is continually conducted until $\mathrm{H}_{2} \mathrm{O}_{2}$ is completely decomposed to form hydroxyl radicals.

\subsection{Catalytic oxidative desulfurization of gasoline}

The oxidative desulfurization ability of $\mathrm{C}_{3} \mathrm{H}_{6} \mathrm{O}_{2} / 0.5 \mathrm{ZnCl}_{2}$ for the FCC gasoline (sulfur content of $303 \mathrm{ppm}$ ) was also investigated. As shown in Table 1, the oxidative desulfurization rate was $66.67 \%$ for gasoline with reaction temperature of $30{ }^{\circ} \mathrm{C}$, an $\mathrm{H}_{2} \mathrm{O}_{2} / \mathrm{S}$ molar ratio of 4 and volume ratio of DESs to oil of $0.15 / 1$. The oxidative desulfurization rate of gasoline is lower than that of model oil (99.42\%) due to the presence of more complex sulfur compounds in gasoline oil. ${ }^{\mathbf{4 1}}$

In this study, desulfurization effect of $\mathrm{C}_{3} \mathrm{H}_{6} \mathrm{O}_{2} / 0.5 \mathrm{ZnCl}_{2}$ is compared with relevant research about different acidic ionic liquids and DESs were used for oxidative desulfurization, whose results are listed in Table 1 . As shown in Table 1, compared with desulfurization research of other acidic ionic liquids, the experimental results show that $\mathrm{C}_{3} \mathrm{H}_{6} \mathrm{O}_{2} / 0.5 \mathrm{ZnCl}_{2}$ has higher desulfurization activity for model oil and gasoline. Meanwhile, on the basis of our previous research, ${ }^{28}$ milder reaction conditions are achieved with $\mathrm{C}_{3} \mathrm{H}_{6} \mathrm{O}_{2} / 0.5 \mathrm{ZnCl}_{2}$ DESs as an extractant and catalyst and $\mathrm{H}_{2} \mathrm{O}_{2}$ as oxidant. Furthermore, $\mathrm{C}_{3} \mathrm{H}_{6} \mathrm{O}_{2} / 0.5$ $\mathrm{ZnCl}_{2}$ DESs exhibit some advantages such as simple synthesis method, mild reaction conditions and easily obtainable raw material.

\section{Conclusions}

In this study, a series of propionic acid-based DESs with different molar ratios of $\mathrm{ZnCl}_{2}$ were used. The oxidative desulfurization system with $\mathrm{C}_{3} \mathrm{H}_{6} \mathrm{O}_{2} / 0.5 \mathrm{ZnCl}_{2}$ DESs as a catalyst and extractant and $\mathrm{H}_{2} \mathrm{O}_{2}$ as an oxidant was investigated. $\mathrm{H}_{2} \mathrm{O}_{2}$ was decomposed into hydroxyl excited state $\left({ }^{\circ} \mathrm{OH}\right)$ under the action of $\mathrm{Zn}^{2+}$ from $\mathrm{C}_{3} \mathrm{H}_{6} \mathrm{O}_{2} / 0.5 \mathrm{ZnCl}_{2}$ DESs. The reaction conditions, including different acidity DESs, reaction temperature, $\mathrm{H}_{2} \mathrm{O}_{2} / \mathrm{S}$ molar ratio, volume ratio of DESs to oil and recycling of DESs, were optimized. The optimal reaction conditions of $30{ }^{\circ} \mathrm{C}$, an $\mathrm{H}_{2} \mathrm{O}_{2} / \mathrm{S}$ molar ratio of 4 and volume ratio of DESs to oil of $0.15 / 1$ were obtained. Desulfurization rates of DBT, 4,6-DMDBT, gasoline up to $99.42 \%, 98.8 \%, 66.67 \%$, respectively, were obtained. The propionic acid-based DESs might be a novel option in the desulfurization process to achieve clean fuel.

\section{Conflicts of interest}

There are no conflicts to declare.

\section{Acknowledgements}

The authors acknowledge the financial support of the Natural Science Foundation of China (Project no. 21003069) and the Doctoral Fund of Liaoning Province (201501105).

\section{References}

1 W. Zhu, H. Li, X. Jiang, et al., Green Chem., 2008, 10(6), 641646.

2 S. Ribeiro, C. M. Granadeiro, P. Silva, et al., Catal. Sci. Technol., 2013, 3(9), 2404-2414.

3 C. Yansheng, L. Changping, J. Qingzhu, et al., Green Chem., 2011, 13(5), 1224-1229. 
4 P. S. Kulkarni and C. A. M. Afonso, Green Chem., 2010, 12(7), 1139-1149.

5 X. M. Yan, Z. Mei, P. Mei, et al., J. Porous Mater., 2014, 21(5), 729-737.

6 J. Chen, C. Chen, R. Zhang, et al., RSC Adv., 2015, 5(33), 25904-25910.

7 J. Xiong, W. Zhu, W. Ding, et al., Ind. Eng. Chem. Res., 2014, 53(51), 19895-19904.

8 X. Tang, Y. Zhang, J. Li, et al., Ind. Eng. Chem. Res., 2015, 54(16), 4625-4632.

9 R. Abro, A. A. Abdeltawab, S. S. Al-Deyab, et al., RSC Adv., 2014, 4(67), 35302-35317.

10 C. Mao, R. Zhao, X. Li, et al., RSC Adv., 2017, 7(21), 1280512811.

11 J. Zhang, W. Zhu, H. Li, et al., Green Chem., 2009, 11(11), 1801-1807.

12 S. Cui, F. Ma and Y. Wang, React. Kinet. Catal. Lett., 2007, 92(1), 155-163.

13 H. Lü, J. Gao, Z. Jiang, et al., Chem. Commun., 2007, 2, 150152.

14 C. Ma, B. Dai, P. Liu, et al., J. Ind. Eng. Chem., 2014, 20(5), 2769-2774.

15 K. J. Stanger and R. J. Angelici, Energy Fuels, 2006, 20(5), 1757-1760.

16 S. Xun, W. Zhu, D. Zheng, et al., RSC Adv., 2015, 5(54), 4352843536.

17 F. Ilgen, D. Ott, D. Kralisch, et al., Green Chem., 2009, 11(12), 1948-1954.

18 Q. Zhang, K. D. O. Vigier, S. Royer, et al., Chem. Soc. Rev., 2012, 41(21), 7108-7146.

19 Z. S. Gano, F. S. Mjalli, T. Al-Wahaibi, et al., Chem. Eng. Process., 2015, 93, 10-20.

20 C. Li, D. Li, S. Zou, et al., Green Chem., 2013, 15(10), 27932799.

21 Z. S. Gano, F. S. Mjalli, T. Al-Wahaibi, et al., Int. J. Chem. Eng., 2015, 6(5), 367.
22 J. Li, H. Xiao, X. Tang, et al., Energy Fuels, 2016, 30(7), 54115418.

23 J. Yin, J. Wang, Z. Li, et al., Green Chem., 2015, 17(9), 45524559.

24 H. Lü, P. Li, C. Deng, et al., Chem. Commun., 2015, 51(53), 10703-10706.

25 W. Liu, W. Jiang, W. Zhu, et al., J. Mol. Catal. A: Chem., 2016, 424, 261-268.

26 W. Zhu, C. Wang, H. Li, et al., Green Chem., 2015, 17(4), 2464-2472.

27 W. Zhu, P. Wu, L. Yang, et al., Chem. Eng. J., 2013, 229, 250256.

28 C. Mao, R. Zhao and X. Li, Fuel, 2017, 189, 400-407.

29 M. Francisco, A. van den Bruinhorst and M. C. Kroon, Green Chem., 2012, 14(8), 2153-2157.

30 H. Lü, S. Wang, C. Deng, et al., J. Hazard. Mater., 2014, 279, 220-225.

31 S. I. Hsiu, J. F. Huang, I. W. Sun, et al., Electrochim. Acta, 2002, 47(27), 4367-4372.

32 Y. Dong, Y. Nie and Q. Zhou, Chem. Eng. Technol., 2013, 36(3), 435-442.

33 X. Chen, H. Guo, A. A. Abdeltawab, et al., Energy Fuels, 2015, 29(5), 2998-3003.

34 H. Gao, C. Guo, J. Xing, et al., Green Chem., 2010, 12(7), 12201224.

35 W. S. Zhu, H. Li, Q. Q. Gu, et al., J. Mol. Catal. A: Chem., 2011, 336(1), 16-22.

36 C. Komintarachat and W. Trakarnpruk, Ind. Eng. Chem. Res., 2006, 45(6), 1853-1856.

37 L. Li, J. Zhang, C. Shen, et al., Fuel, 2016, 167, 9-16.

38 H. F. M. Zaid, F. K. Chong and M. I. A. Mutalib, Fuel, 2017, 192, 10-17.

39 P. Wu, B. Dai, Y. Chao, et al., J. Mol. Catal., 2017, 436, 53-59.

40 M. Zhang, W. Zhu, H. Li, et al., Chem. Eng. J., 2014, 243, 386393.

41 W. Zhu, G. Zhu, H. Li, et al., J. Mol. Catal. A: Chem., 2011, 347(1), 8-14. 